American Journal of Applied Sciences 9 (5): 666-672, 2012

ISSN 1546-9239

(C) 2012 Science Publications

\title{
The Role of Information Systems in Implementing Total Quality Management
}

\author{
${ }^{1}$ Ahmad Zakaria Siam, ${ }^{2}$ Khalid Alkhateeb and ${ }^{3}$ Sami Al-Waqqad \\ ${ }^{1}$ Department of Banking and Finance, Al Balqa Applied University, Jordan \\ ${ }^{2,3}$ Department of Accounting, \\ Faculty of Adminstrative and Financial Sciences, Petra University Jordan
}

\begin{abstract}
Problem statement: The aim of this study is to identify the extent to which Information Technology (IT) has been used to support TQM in order to identify the role of IT in implementing Total Quality Management (TQM). The primary emphasis of this study was on how IT provides help and supports in TQM processes rather than on TQM performance. This has many policy implications for different firms that are welling to enhance the role of IT in different aspects of their TQM. Approach: The questionnaire survey was used as the data collection method. Data were analysed using SPSS programme. This study is limited only to the managers of operations departments in different companies at Sohar Industrial Estate in Oman. Results: The results of the research indicate that the usage of IT is not the same among the different TQM dimensions. The highest level of IT support was used in information and analysis, output quality assurance and important innovation. While the lowest level of IT support was used in quality results and supplier quality assurance. Conclusion/Recommendations: As IT role should be enhanced in modifying work processes in order to improve product quality and productivity. Value and international implications: This study is the first to be applied in Gulf area, an area that exhibits arapid groth and presence of international companies.
\end{abstract}

Key words: Total quality management, information technology, sohar industrial city

\section{INTRODUCTION}

The increasing global competitive nature of the business environment has forced companies to develop strategies to become low cost producers and to differentiate their goods and services from their competitors. Through customer-focused quality programs, quality reduces the cost and became a powerful product differentiation to customers. In order to be successful, firms must view quality as an essential part of their strategic process.

Total Quality (TQ) is a formidable tool of competitiveness. It is therefore essential to define TQ in terms of this competitiveness. Put it as simple as possible, competitiveness is the quality of being able to compete, which means two things:

- The capacity to keep and not therefore lose, the customers already gained

- The capacity to attract and win new customers

Total Quality Management (TQM), evolved from many different management practices and improvement processes (Magutu, 2010). As supported by Katiro Ishikawa in Japan and Fiegenbaum in the U.S., TQM involves management and control of quality throughout the entire organization (Besterfield, 2006; Wong, 2006; Singh et al., 2011). In TQM marketing department collects the customer expectation data using market survey and provides them to product development and design department. Product development and design department in turns designs a selected variety of products to best match the needs and expectations of the target customers as provided by the marketing department and pass the drawings to manufacturing department for fabrication and assembly. Then, manufacturing department makes parts and assembles the products according to design specifications. Quality control department regularly monitors and inspects production and assemble processes to make sure that parts and assemblies are produced according to product design specifications. Packaging and distribution's responsibility is to package and deliver the product to the customers undamaged and at just in time (Ferguson, 2000). TQM emphasizes on customer focus. Product quality is commonly defined as the product's fitness for its intended use which means how well the product meets the needs and expectation of customers. Again, 
Am. J. Applied Sci., 9 (5): 666-672, 2012

different customers have different needs and expectations. Therefore, a product must be designed to meet the needs and expectations of target customers (Anderson and Adams, 1997).

What is IS? Effective application of technology is becoming critical to the success of an organization. Virtually all business and governmental organizations use some form of technology-based information system to support their decision-making processes. While the study of these systems can be found under many different names, such as Management Information Systems (MIS), Information Technology (IT) and Information Resource Management (IRM), we use the general term "Information Systems" or IS to represent this discipline of study. IS encompasses two broad areas:

- Acquiring, deploying and managing technologybased systems in business, government and other organizations

- Designing, developing and implementing technology-based systems

The study of IS incorporates both the development and use of technology to facilitate organizations' processes. IS bridges the gap between the actual development of fundamental computer tools and the use of those tools. People interested in IS are curious about the effect of technology-based tools on such areas as decision-making, cooperation, learning, leading, negotiating and business processes. Thus, students and scholars studying this area must have a good understanding of how people interact in organizations. Students' majoring in IS learn how to develop information systems as well as how to actually apply the use of those systems in organizations. Students are exposed to fundamental business concepts so that they can communicate effectively with other business professionals. Students also develop a strong understanding of technology so that they can work with other technical professionals and perform technical work on their own.

What is TQM and what constitutes TQM? Total quality management is a management approach that originated in the 1950's and has steadily become more popular since the early 1980's. Total Quality is a description of the culture, attitude and organization of a company that strives to provide customers with products and services that satisfy their needs. The culture requires quality in all aspects of the company's operations, with processes being done right the first time and defects and waste eradicated from operations.
Total Quality (TQ) constitutes a new managerial method, a new system of values, new priorities as a basis of decision making, a new way of managing human resources, a new and more concrete approach to problem solving as well as far too many concepts. In other words, TQM is a management approach for improving organizational performance that encompasses a variety of topics both technical and behavioral. Deming, for example, prescribed TQM in 14 points which he claimed to be a set of principles to remain competitive in providing products and services (Deming, 1986). Anderson (1994) studied Deming principles and developed a conceptual framework for TQM using seven concepts, which include visionary leadership, internal and external communication, learning, process management, continuous improvement, employee fulfillment and customer satisfaction.

Juarn (1992) described his version of TQM through a "trilogy" of management processes: quality planning, quality control and quality improvement. Crosby (1979) prescribed a 14 steps quality program that focused on how to change organizations using management and organizational processes rather than statistical tools and techniques. Thus, the program is primarily behavioral and its audience is mainly top management.

Waldman (1994) summarized the above approaches to quality management and identified the following eight elements of TQM:

- Upper management commitment to place quality as a top priority

- A broad definition of a quality as meeting customers' expectations at the least cost, which encompasses all phases of the design, production and delivery of a product/service

- The institution of leadership practices oriented toward TQM values and vision

- The development of a quality culture

- Involvement and empowerment of all organizational members in cooperative efforts to achieve quality improvements

- An orientation toward managing-by-facts, including the prolific use of scientific and problem solving process control

- The continuous commitment to improve employees' capabilities and work processes through training and benchmarking respectively

- Attempts to get external suppliers and customers involved in TQM efforts

Aim of the study: The aim of this study is to identify the extent to which Information Technology (IT) has 
been used to support TQM at Sohar Industrial City in Oman in order to identify the role of IT in implementing TQM. The primary emphasis of this study was on how IT provides help and supports in TQM processes rather than on TQM performance.

Literature review: There has been extensive literature on the relationship between TQM and. In a survey of 110 public organizations getting the Malaysian Prime Mister's Quality Award, Ang et al. (2000) successes in developing QMSIT construct that can be used to evaluate the QM-IT relationships. The nine dimensions of quality management system supported by IT are leadership, strategic planning process, output quality assurance, important innovations, information and analysis, human resource utilization, customer satisfaction and quality results.

Fok et al. (2001) surveyed 221 managers in the Southern United States. Where TQM (including three major variables such as use of TQM programs, perceived influence on quality issues and understanding of TQM techniques/ concepts) is adopted more fully, there will be a significant impact on four areas of IS development: system goals; system design philosophy/concepts; assumptions made by IS professionals about system users and user involvement in system development. Both TQM and IT may require similar organizational culture. Dewhurst et al. (2003) investigated 14 Spanish companies, in which 13 companies with ISO 9000 certificate and one without, which obeyed strict governmental norms. Ooi (2009) reviewed different letretures on the relationship between different dimision of TQM and Knowledge Management and found that TQM process supports Knoledge Managements effors.

Dimensions of the study: After conducting an extensive revision of the related theoretical and practical literature and due to the comprehensiveness of the nine dimensions identified and classified by Finlay and his colleagues, the researchers decided to use them as a base of collecting the primary data required for this study (Ang et al., 2001). The dimensions are as follows:

- Leadership

- Strategic planning process

- Output quality assurance

- Supplier quality assurance

- Important innovations

- Information and analysis

- Human resources utilization

- Customer satisfaction

- Quality results
Leadership: It is possibly the most important element in TQM. It appears everywhere in organization. Leadership in TQM requires the manager to provide an inspiring vision, make strategic directions that are understood by all and to instill values that guide subordinates. For TQM to be successful in the business, the supervisor must be committed in leading his employees. A supervisor must understand TQM, believe in it and then demonstrate their belief and commitment through their daily practices of TQM. The supervisor makes sure that strategies, philosophies, values and goals are transmitted down throughout the organization to provide focus, clarity and direction. A key point is that TQM has to be introduced and led by top management. Commitment and personal involvement is required from top management in creating and deploying clear quality values and goals consistent with the objectives of the company and in creating and deploying well defined systems, methods and performance measures for achieving those goals. Top management support is the single most important factor needed for implementation of TQM for IS and better quality of services is presumed to be the most important benefit realized by the firm (Siddiqui and Rahman, 2006). However, it should be noted that sometimes, TQM is not directly absorbed by managers, but they tend to see it from the technical point of view, being aware only of the importance of its "hard" aspects (Psychogios and Priporas, 2007).

Strategic planning process: One way of seeing quality is to define it as conformity, consistency, or the reduction/absence of variation. This means that quality implies the existence of systematized planning, routine making and checks, capable of keeping processes within predetermined limits. Strategic quality plans are the glue that holds companies' quality effort together (Garvin, 1991). As is the case in any process instigated by management and put into action from the top down, planning follows a track. That is, there no place for out-of-the-box thinking, or seeking solutions that is not part of the plan.

In this sense, quality management can be taken to mean rigorous planning and reduction of uncertainty. The recourse to plans, programs, multi-point data checklists, or statistical control systems is the most visible part of quality's management by planning. The process of the planning itself enables organizations to identify their customers' needs and requirements, prioritize their requirements, make employees fully aware and become committed to the quality goals of their organizations (Harrington, 1997). Recently, it has been argued that Enterprise Resources Planning systems implementation can be successful if it is preceded by a TQM focus (Li et al., 2008). 
Quality assurance: In many organizations, it is important to address organizational culture in the early stages of implementation of a quality improvement process. Often, a first step in developing a quality culture is the establishment of values that will be held by the organization. It is usually necessary to include employees at all levels in the development of these values in order to help create buy-in and an increased motivation to hold and follow through with these values.

Once values have been set, strategies have been developed and goals have been defined, it is important that these values are deployed throughout the organization to ensure complete employee knowledge and understanding. As employees become more and more educated in the values, strategies and goals of the initiatives; their ability to become more deeply involved in the quality processes. This involvement strengthens the commitment and ownership employees have in the elements necessary to develop a quality culture. Management should also understand that their attitude and leadership styles should change as necessary in accordance with the values of the organization. Since quality includes the involvement of employees and not a controlling atmosphere, management may have to adjust.

The primary role of introducing a quality assurance process is to ensure that the different types of goods produced or services offered is of the desired quality and satisfy the actual needs and wants they are actually produced for. Quality assurance therefore is a framework that encapsulates four principles of control, i.e., setting standards, appraising conformance to these standards, acting to ensure standards are met and planning for improvement in standards, to provide an integrated system for managing all functions within an organization (Lin, 1991). It has been found that the introduction of IT on quality management has contributed greatly to the enhancement of quality awareness (Mjema et al., 2005).

Supplier quality assurance: Organizations wishing to produce quality products must obtain quality inputs. Supplier quality has a great effect on an organization's quality assurance. While certain steps can be taken to accomplish this in the genesis phase (e.g., investigating suppliers for levels of quality, reducing the number of suppliers. lengthening contracts with those suppliers that provide quality products in order to show a commitment to them), most of the work of supplier quality management must occur in the late genesis phase or during the maintenance phase. The maintenance phase sees increased involvement with suppliers to develop quality relationships. This is intuitive since it is expected that an organization that is growing in quality knowledge will be increasingly able to impart quality knowledge to its suppliers.
Important innovation: Innovation is necessary to maintain quality that addresses client needs in order to sharpen the organization's adaptive skills and exercise its exploratory learning. The quest for quality requires reduced unwanted variation in products or services and adherence to predetermined standards. However, there should be a balance between innovation and standardization (Oakland, 1993) as TQM means continuous improvement. Pursuit of new technology for strategic advantage, whether by designing and introducing new products or services, or by creating innovative work processes, is critical for TQM success.

Information and analysis: TQM is an informationintensive management. Information plays a vital role as all quality improvement activities are based on informed decision-making (Terziovski et al., 1996). A company's database must be comprehensive and cover all critical areas such as customers, suppliers, employees and projects/processes (Flynna et al., 1994). As managing quality generates a great deal of data, it is important to determine what data types are worth keeping and how to organize them into an easily accessible structure. The databases must be able to facilitate different data manipulation and in-depth analysis to fulfill information requirements of each level (strategic, tactical and operational) of decisionmaking activities (Zahedi, 1998).

Human resources utilization: A good number of the problems encountering the implementation of sustainable TQM are to do with the involvement and commitment of employees to achieving quality goals (Miller, 1996). Involvement and empowerment of employees seem to be of vital importance in implementing TQM. It appears that the importance of these factors increases as the quality effort matures. In implementing a TQM, it is important to jointly involve employees and management in order to promote ownership and commitment. As these elements are put in place, training plays a key role in developing the skills necessary to allow continual employee involvement and empowerment. For example, introducing employees to different statistical techniques provide them with the means for quantitatively monitoring shop floor operations. In addition, concepts such as suggestion systems and the provision of problem-solving techniques allow for increased involvement. As employees grow in their knowledge and problem-solving ski11s, management typically respond by providing increased levels of empowerment.

Customer satisfaction: Ultimately, quality is determined by the customer; therefore. it is important 
for any organization to place immediate attention on customer focus. Customer focus is probably the lead factor in helping organizations determine their vision for the future. As customer needs are identified, the appropriate customer-focused strategies necessary for meeting them can then he developed. It is extremely important, however, that close contact be maintained with customers so as to continually Identify changing needs. Common methods of identifying changing customers needs include focus groups, routine surveys, visits to customer sites, visits from customers, customer input on new products, market tests and formal complaint management systems.

Quality results: All activities performed and conducted by an organization should be measured in order to achieve sustainable improvement, satisfying customer requirements, justifying the use of resources and detecting quality problems (Oakland, 1993). Therefore, quality should encompass product and services quality, productivity, waste reduction and elimination, customer and employee satisfaction (Oakland, 1993). The following table provide a review for letrerture .

Research hypothesis: Based on the literature reviews and the dimensions discussed above Hypothesis and Objectives Based on the philosophy of TQM and its applicability to IS functions we drew the hypothesis that:

- "Information technology is used to support the different dimensions of TQM"

- This hypothesis was tested for the 9 dimensions discussed above

\section{MATERIALS AND METHODS}

\section{Research methodology:}

The Study Population: Since the study is limited only to study the managers of operations departments in different companies at Sohar Industrial Estate and the number is 42 , researchers decided to study the whole population. Out of the 42 questionnaires mailed, 36 were returned and used for analysis. The response rate (86\%) is considered very high with studies of this nature.

Data and statistical analysis: The questionnaire survey contained many questions related to each dimension discussed about. 7 points Likert Scale was employed in the survey. All the items measuring TQM, IS and IS impact on TQM, were measured on a 1-7 scale where a score of 1 "no use "and 7 represented "extensive use". Data analysis was performed using SPSS program. Reliability for the all the study's concepts was measured using the internal consistency method (Bohrnstedt, 1970). Mean and Standard Deviation Measures was employed in the statistical analysis.

\section{RESULTS AND DISCUSSION}

By looking at Table 1 which presents the mean and standard deviation related to different dimensions of the study, it can be easily noticed that all companies participated in the study are using Information Technology (IT) in support of Total Quality Management (TQM) along the nine different dimensions. The mean for questions addressing the use of IS in supporting all dimensions of TQM is above 4.5 on a seven-point scale for all of them except two (supplier quality assurance and quality results) which have a mean less than 4.5 but above 4.00. All companies reported that they have used a moderate to a maximum feasible amount of IT to support the information and analysis. More than $85 \%$ of the companies reported that they have used a moderate to a maximum feasible amount of IT to support the 'output quality assurance' (number of respondents $=35$ ), the 'importance innovation' (36), the 'leadership' (32),the 'strategic planning process' ((31) and the 'customer satisfaction' (31). 66\% of the companies indicated that they have used below the moderate level of IT to support 'quality results' and $61 \%$ of them used below the moderate level of IT to support the 'supplier quality assurance'. Table 1 also indicates that the 'information and analysis' has the highest level of IT use (mean $=5.83$ ), followed by the 'output quality assurance' (5.28). The 'supplier quality assurance' has the lowest mean of IT use (4.08). For exact mean of IT use, please see Table 1. The overall mean of use of IT to support TQM is also presented in Table 1 which is 4.87 .

Table 1: Extent of IT usage

\begin{tabular}{lll}
\hline Dimensions & Mean & Standard deviation \\
\hline Information and analysis. & 5.83 & 0.87 \\
Output quality assurance. & 5.28 & 0.88 \\
Important innovations. & 5.12 & 0.99 \\
Customer satisfaction. & 4.92 & 1.38 \\
Leadership & 4.89 & 1.12 \\
Strategic Planning Process. & 4.83 & 1.18 \\
Human resources utilization. & 4.55 & 1.46 \\
Quality results. & 4.33 & 1.57 \\
Supplier quality assurance. & 4.08 & 1.57 \\
Overall IT use in TQM & 4.87 & 0.52 \\
Measured on seven-point scale & & \\
\hline
\end{tabular}




\section{CONCLUSION}

This study provides empirical evidences on the role of IT in supporting the implementation of TQM. The results of the study indicate that the IT benefits TQM implementation more in the 'information and analysis', 'output quality assurance', the 'important innovation', the 'customer satisfaction', the 'leadership' and the 'strategic planning process'. Despite the fact that the previous literatures of operations management provide examples to demonstrate how IT can be used and deployed to support the 'quality results' and 'quality supplier assurance', this study found that the IT usage level of these two dimensions was only moderate.

When comparing the results of this study to the few empirical results reported in the literature of operations management, one can see that the results of this study support the results of some previous studies in some cases; and did not support the findings of others. The difference in the context of the study may account for the variation in the results.

The results of this study suggest that managers seeking help from IT to implement TQM could start with information and analysis, quality assurance and important innovations dimensions. IT could play a pivot role in modifying work processes in order to improve product quality and productivity. IT could also play a significant role in developing and maintaining a comprehensive database of employees, company, suppliers, customers and process.

Based on the previous discussion, one can easily recognize the crucial role which IT can have in implementing TQM. As a matter of fact. The role of IT should even expand and increase more and more in manufacturing and industrial sector in particular in order for companies to enhance all different aspects of operations/processes.

\section{REFERENCES}

Anderson, E. and D.A. Adams, 1997. Evaluating the success of TQM implementation. Product. Inventory Manage. J. APICS, Falls, Church, 6: 1-6.

Anderson, J.C., 1994. A Theory of Quality management underlying the deming management method. Acad. Manage. Rev., 19: 472-509.

Ang, C.L., M. Davies and P.N. Finlay, 2000. Measures to assess the impact of information technology on quality management. Int. J. Quality Reliability Manage., 17 : 42-65. DOI: 10.1108/02656710010300135

Ang, C.L., M. Davies and P.N. Finlay, 2001. An empirical study of the use of information technology to support total quality management. Total Quality Manage., 12: 145-157. DOI: 10.1080/09544120120011370
Besterfield, D.H., 2006. Total Quality Management. 3rd Edn., Academic Internet Publishers, S.1., ISBN-10: 1428807195, pp: 264.

Bohrnstedt, G.W., 1970. Attitude Measurement. 2nd Edn., Rand McNally, Chicago, pp: 568.

Crosby, P.B., 1979. Quality is Free: The Art of Making Quality Certain. 1st Edn., McGraw-Hill, New York, pp: 270.

Deming, W.E., 1986. Out of the Crisis. 1st Edn., Center for Advanced Engineering Study, Cambridge, pp: 507.

Dewhurst, F.W., A.R. Martinez-Lorente and C. Sanchez-Rodriguez, 2003. An initial assessment of the influence of IT on TQM: A multiple case study. Int. J. Operat. Product. Manage., 23: 384-374. DOI: $10.1108 / 01443570310467302$

Ferguson, B., 2000. Implementing supply chain management. Product. Inventory Manage. J., APICS, Falls, Church.

Flynna, B.B., R.G. Schroederb, S. Sakakibara, 1994. A framework for quality management research and an associated measurement instrument. J. Oper. Manage., 11: 339-366. DOI: 10.1016/S02726963(97)90004-8

Fok, L.Y., V.M. Fok and S. Hartman, 2001. Exploring the relationship between total quality management and information systems development. Inform. Manage., 38: 355-371. DOI: 10.1016/S03787206(00)00075-6

Garvin, D.A., 1991. How the Baldrige award really works. Harvard Bus. Rev., 69: 80-95.

Harrington, H.J., 1997. The fallacy of universal best practice. TQM Magazine, 9: 61-75. DOI: 10.1108/09544789710159461

Juarn, J.M., 1992. Juarn on Quality by Design, New York: Free Press

Li, L., C. Markowski, L. Xu and E. Markowski, 2008. TQM-A predecessor of ERP implementation. Int. J. Product. Econ., 115: 569-580. DOI: 10.1016/j.ijpe.2008.07.004

Lin, B., 1991. Quality control information systems in manufacturing: Considerations and concerns for management. Int. J. Oper. Product. Manage., 11: 41-50. DOI: $10.1108 / 01443579110001211$

Magutu, 2010. Management Through Effective Information Quality Management (IQM) in banking services. AJBUMAm, 1: 96-111.

Miller, H., 1996. The multiple dimensions of information quality. Inform. Syst. Manage., 13: 7982. DOI: $10.1080 / 10580539608906992$

Mjema, E.A.M., M.A.M Victor and M.S.M Mwinuka, 2005. Analysis of roles of IT on quality management. TQM Mag., 17: 364-374. DOI: 10.1108/09544780510603206 
Oakland, J.S., 1993. Total Quality Management: The Route to Improving Performance. 2nd Edn.,, Butterworth Heinemann, Oxford, ISBN-10: 0750609931, pp: 463.

Ooi, K.B., 2009. TQM and knowledge management: Literature review and proposed framework. Afr. J. Bus. Manage., 3: 633-643.

Psychogios, A.G. and C.V. Priporas, 2007. Understanding total quality management in context: Qualitative research on managers' awareness of TQM aspects in the Greek service industry. Qualitative Report, 12: 40-66.

Singh, T., P. Giteeka and R. Dubey, 2011. A theoretical framework for soft dimensions of total quality management. Proceedings of the International Conference on Economics and Finance Research, (IACSIT' 11), Press, Singapore, pp: 529-533.
Terziovski, M., A. Sohal and D. Samson, 1996. Best practice implementation of total quality management: Multiple cross-case analysis of manufacturing and service organizations. Total Quality Manage., 7: 459-481. DOI: 10.1080/09544129610586

Waldman, D.A., 1994. The contribution of total quality management to a theory of work performance. Acad. Manage. Rev., 19: 510-536.

Wong, K.Y., 2006. Critical success factors for implementing knowledge management in small and medium enterprises. Ind. Manage. Data Syst., 105: 261-279. DOI 10.1108/02635570510590101

Zahedi, F.M., 1998. Quality information systems: A unifying framework. Int. J. Technol. Manag., 16: 446-465. DOI: 10.1504/IJTM.1998.002683 